Научная статья

УДК 369.8

DOI: $10.17213 / 2075-2067-2021-5-113-120$

\title{
СОЦИАЛЬНО-ЭКОНОМИЧЕСКИЕ ПРАВА И ИХ РОЛЬ В ОБЕСПЕЧЕНИИ ЗАЩИЩЕННОСТИ ЧЕЛОВЕКА
}

\author{
Наталья Александровна Левченко ${ }^{1 凶}$, \\ Светлана Александровна Иващенко², Елена Валерьевна Романенко \\ ${ }^{1,2,3}$ Южно-Российский государственный политехнический университет (НПИ) \\ имени М. И. Платова, г. Новочеркасск, Россия \\ ${ }^{1}$ levchenckona@yandex.ru ${ }^{凶}$, ORCID: 0000-0002-4016-788X, AuthorID РИНЦ: 366454 \\ 2r29nikols@yandex.ru, ORCID: 0000-0002-3352-3807, AuthorID РИНЦ: 697950 \\ ${ }^{3}$ romanenko1971@yandex.ru, ORСID: 0000-0002-9097-7071, AuthorID РИНЦ: 756734
}

Аннотация. Целью является обоснование сочиальной политики в России с учетом современных сочиальных, экономических и политических реалий и особенностей сочиальных прав.

Методологию представляют теоретические аспекты сочиальных прав, рассматривающие их в менее универсальном аспекте, чем гражданско-политические права. Реализачия насущчных сочиильно-экономических проблем, стоящих перед государственными органами управления, требует более детального анализа социальных прав, как с теоретической точки зрения, так и на уровне специиальных отраслевых исследований.

Результаты. Одним из важных результатов исследования является определение сочиальных прав как права индивида, реализуемого через систему сочиальных гарантий, экономических возможностей общества. Рассмотренные особенности социальных прав требуют более тщцательного изучения с учетом современной социально-экономической ситуачии.

Перспективу исследования составляет всесторонний анализ сочиально-экономических прав с учетом конкретных содержательных и сущуностных аспектов, позволяюших отразить специфические особенности социальных прав.

Ключевые слова: сочиальные права, общество, демократическое общество, сочиальные нормативы, социальная защита, социальная политика, трудовая деятельность, уровень жизни

Для цитирования: Левченко Н.А., Иващенко С.А., Романенко Е.В. Социально-экономические права и их роль в обеспечении защищенности человека // Вестник Южно-Российского государственного технического университета. Серия: Сочиально-экономические науки. 2021. T. 14, №5. C. 113-120. http://dx.doi.org/10.17213/2075-2067-2021-5-113-120.

Original article

\section{SOCIO-ECONOMIC RIGHTS \\ AND THEIR ROLE IN ENSURING HUMAN SECURITY}

\author{
Natalya A. Levchenko ${ }^{1 凶,}$ \\ Svetlana A. Ivashchenko ${ }^{2}$, Elena V. Romanenko ${ }^{3}$
}

(C) Левченко Н.А., Иващенко С.А., Романенко Е. В., 2021 
${ }^{1,2,3}$ Platov South Russian State Polytechnic University (NPI), Novocherkassk, Russia

${ }^{1}$ levchenckona@yandex.ru ${ }^{\bowtie}$ ORCID:0000-0002-4016-788X, AuthorID RSCI: 366454

${ }^{2}$ r29nikols@yandex.ru, ORCID:0000-0002-3352-3807, AuthorID RSCI: 697950

${ }^{3}$ romanenko1971@yandex.ru, ORCID:0000-0002-9097-7071, AuthorID RSCI: 756734

Abstract. The purpose of the study is to substantiate social policy in Russia, taking into account modern social, economic and political realities and the peculiarities of social rights.

The methodological basis is the theoretical aspects of social rights, which consider them in a less universal aspect than civil and political rights. The implementation of modern socio-economic tasks of the state requires a more thorough study of social rights both in the theoretical aspect and at the level of special industry research.

Research result. One of the important results of the study is the definition of social rights as the rights of an individual, implemented through a system of social guarantees, economic opportunities of society.

The prospect of the study is a comprehensive analysis of socio-economic rights, taking into account specific content and essential aspects that allow us to reflect the specific features of social rights.

Keywords: social rights, society, democratic society, social norms, social protection, social policy, labor activity, standard of living

For citation: Levchenko N.A., IvashchenkoS.A., Romanenko E.V. Socio-economic rights and their role in ensuring human security // Bulletin of the South Russian State Technical University. Series: Socio-economic Sciences. 2021; 14 (5): 113-120. (In Russ.). http://dx.doi. org/10.17213/2075-2067-2021-5-113-120.

Введение. Весь комплекс прав гражданина обладает свойствами целостности и взаимосвязанности, таким образом, можно говорить о том, что социально-экономические права не менее значимы, чем политические или гражданские. Все существующие права образуют единый комплекс правового статуса личности, что в свою очередь налагает на государственные органы обязанность предпринимать комплекс законодательных и административных мер, необходимых для осуществления в полной мере прав и свобод гражданина. Более того, государство предусматривает право каждого человека на судебную защиту своих прав (социальных, политических, гражданских).

Термин «социальные права» появился в начале XX века в конституциях большинства европейских государств. А. Бланкенагель отмечает, что все существующие конституции «отражают и синтезируют социальные вопросы, в силу определенных особенностей которых обнаруживаются весьма специфические проблемы» [2, с. 9]. Это связано с тем, что «социальные права» - термин сам по себе достаточно парадоксальный. Во множестве научных разработок социальные права рассматриваются в границах социальноэкономических прав без учета конкретизации содержательных и сущностных мнений, позволяющих анализировать особую «социальную» природу, которая выделяет их из общего ряда других прав [3].

Авторы В. А. Иваненко и В.С. Иваненко констатируют, что «социальные права человека, которые законодательно признаются, закрепляются и расширяются, конституционно гарантируются, юридически обеспечиваются и защищаются, не имеют при этом общепризнанного или согласованного своего перечня» [5, с. 98].

Теоретико-практические аспекты понятия социальных прав. Большую практическую ценность имеет вопрос конкретизации социальных прав из общего теоретико-практического комплекса социально-экономических прав и исследований. Обособление соци- 
альных прав предопределено их ролью в обеспечении социальной защищенности человека. На это, в частности, обращала серьезное внимание Е.В. Аграновская: «Признав единственным путем преодоления кризиса путь создания рынка на здоровой экономической основе, государство вместе с тем оказалось перед лицом серьезной проблемы - необходимости социальной защиты людей, обеспечения, прав граждан, в первую очередь создания механизма обеспечения защиты социальных прав» [1, c. 81]. Данное утверждение не утратило актуальности и в настоящее время.

Таким образом, теоретическое понимание социальных прав имеет свои далеко идущие практические последствия. В решении вопросов, отражающих социальные права и нормативы, безусловно, должны соблюдаться требования Конституции РФ. Вместе с тем необходимо учитывать современные социальные, экономические и политические реалии. Осуществляемые в российском обществе трансформации влекут за собой сущностные, глубинные изменения прежних вполне устоявшихся правовых понятий, поэтому отечественная правовая наука должна периодически возвращаться к осмыслению новых аспектов уже известных категорий с учетом реальных изменений, происходящих в общественной жизни.

На сегодняшний день проблема социально-экономических прав по-прежнему вызывает множество дискуссий в научном сообществе. К.Л. Шеппели, например, отмечает, что теоретические разночтения существуют на различных профессиональных уровнях: «Философы вообще выражают сомнения в том, что социальные права действительно можно отнести к сфере прав; теоретики-конституционалисты возражают на том основании, что социальные права отнюдь не основываются на всеобщем согласии и, кроме того, у них нет даже точного определения; а теоретики демократии основывают свои возражения на утверждении, что судебное обеспечение социальных прав связывает руки государства жесткими обязательствами, а это не позволяет ему относиться ко всем нуждам и потребностям демократического общества с равным вниманием» [9, с. 52].

Несмотря на споры в теоретической области, в практическом применении социаль- ные права получают более весомый статус. Немаловажной особенностью социальных прав является доминирование рекомендательного начала. М.И. Фетюхин констатирует, что практическая реализация социальных прав требует больших затрат времени и материальных ресурсов, чем гарантирование основных свобод. Несомненно, что гражданско-политические права значительно более универсальны, чем социальные права человека. Особенно наглядно это выражается в двух отношениях:

1) область реализации социальных прав не вполне универсальна, поскольку в историческом и культурном аспектах она более динамична, кроме того, ее границы подвержены динамическому воздействию в социальном времени;

2) в настоящее время социальные права выступают в их субъектной направленности к незащищенным слоям населения.

Анализируя теоретические аспекты социальных прав, М.И. Фетюхин обращает внимание на то, что данные права отличает меньшая универсальность, определенность, четкость и жесткость изложений по сравнению с комплексом гражданско-политических прав. Комплекс социальных нормативов, используемых в настоящее время, основан на таких понятиях, как «справедливость», «достоинство», «удовлетворение», «разумность» и т.п. Данные определения не являются статичными, изменчивыми и с юридической точки зрения крайне трудно поддаются теоретическому осмыслению. Практическое исследование перечисленных определений требует использование ограниченного числа критериев, норм, социально-экономических требований в каждой конкретной ситуации [8].

Автор Н.В. Путило, подробно исследуя теоретико-практические черты понятия социальных прав, отмечает, что преодоление социально-экономических трудностей, стоящих перед современной Россией, требует более детального исследования социальных прав как в теоретической плоскости, так и на уровне специальных отраслевых исследований [7]. Целесообразно выделить следующие их особенности:

1) социально-экономические права непременно предполагают участие органов государственного управления в реализации 
механизмов социальной защиты населения, а также при осуществлении гражданином своих экономических прав;

2) высокая скоррелированность между процессом осуществления законодательно закрепленных социальных прав и социальноэкономическим потенциалом государства;

3) ограниченность использования защиты социальных прав посредством системы судопроизводства компенсируется использованием других правозащитных механизмов;

4) общим, универсальным объектом для всех социальных прав являются естественные блага цивилизации, локальный характер которых прямо пропорционален эффективной реализации таких понятий, как гармоничное развитие личности и достойный уровень жизни. Социальные права предполагают тесное взаимодействие каждого гражданина c органами государственного управления в выборе направления действий или объекта социального права.

Системный анализ комплекса социально-экономических прав [10]. Проводя системный анализ комплекса социально-экономических прав, следует рассматривать их в следующих содержательных уровнях:

1) непосредственная трудовая деятельность, направленная на получение необходимых средств существования;

2) достижение оптимального уровня жизни и развития общества;

3) право на социальное обеспечение отдельных групп населения.

На основе полученных выводов целесообразно дать определение социальных прав человека как «естественных, неотчуждаемых возможностей, гарантирующих защиту и поддержку со стороны общества и государства в случаях объективной невозможности самостоятельно обеспечить достойные условия существования для себя и своей семьи, обеспечивающих доступность элементарных благ цивилизованного общества» [7, с. 15].

Иную формулировку определению социальных прав рекомендуют В.А. Иваненко и В.С. Иваненко: «Социальные права - это признаваемый обществом и государством и закрепленный в нормативно-правовых актах комплекс прав и свобод, которыми должен обладать каждый человек с целью обеспече- ния и защиты своих определенных свойств, интересов и возможностей, необходимых ему для нормального физиологического, материального и духовного существования и развития, для социально достойной жизни и общественно значимой деятельности» [5, с. 98]. Авторы признают, что социальные права, которые зафиксированы на законодательном уровне большинства современных государств, позволяют каждому гражданину свободно реализовывать в социальной среде свои конституционные права и свободы.

Так, В.В. Гурлев и А.В. Гурлев, проведя всесторонний анализ международного и российского законодательства области социальной защиты, утверждают, что большинство социальных прав человека, отраженных в нормативно-правовых актах и декларациях, соответствуют мировым стандартам и достаточно полно отражают сущность конституционных прав и свобод [4].

Из этого следует, что правовая поддержка основных социальных прав и свобод гражданина в Российской Федерации осуществляется с высокой степенью эффективности. В настоящее время задача органов государственного управления состоит в его дальнейшем развитии и совершенствовании.

Обобщая научные исследования, отражающие теоретический аспект социальных прав, можно констатировать, что в их перечень включаются права, предусмотренные ст. 37-44 Конституции РФ. Их отличает, с одной стороны, прямая зависимость с жизненно важными интересами человека, с другой экономическая структура.

Основная цель социальных прав - предоставление материальных благ для необходимого и достойного жизнеобеспечения человека, включая меры общественной социализации, которая осуществляется посредством обеспечения прав на жилище, охрану здоровья, образование.

Реализация общественных отношений через механизм социальных взаимодействий происходит посредством прав на жилище, охрану здоровья и образование. В то же время не следует подходить к реализации данных социальных прав упрощенно.

Вышеперечисленные права могут осуществляться в различных формах, в том числе на финансовой основе. Конституция РФ 
уделяет особое внимание на социальном аспекте этой группы прав.

Так, право на жилище, закрепленное в Конституции Российской Федерации (статья 40), предполагает уточнение условий реализации данного права. Данные условия охватывают: категории граждан в соответствии с уровнем их совокупного дохода (например, малоимущие), конкретные жилищные фонды, за счет которых происходит реализация данного права, и установление законодательных норм в области предоставлении жилья. В конституционном закреплении права на охрану здоровья (статья 41 Конституции РФ) также большое значение принадлежит социальной составляющей (в узком смысле термина «социальный»). Это, прежде всего, оказание медицинской помощи без взимания платы, определение непосредственных источников финансирования, наличие которых обеспечивает гражданам Российской Федерации бесплатную медицинскую помощь (за счет средств бюджетов различных уровней, страховых взносов), и перечисление категорий учреждений, несущих бремя реализации права на медицинскую помощь (государственные и муниципальные учреждения здравоохранения).

В Конституции РФ отражена общедоступность и бесплатность дошкольного, основного общего и среднего профессионального образования (статья 43), а также определен перечень учреждений образования, которые претворяют в жизнь данное право (государственные либо муниципальные образовательные учреждения). Кроме того, право на образование реализуется посредством установления федеральных государственных образовательных стандартов.

Таким образом, социальные права, отраженные в Конституции Российской Федерации, осуществляются в двух направлениях: во-первых, их реализация происходит через государственные органы, посредством материальных (имущественных) возможностей самого человека, во-вторых, когда государство предусматривает специальные конституционные меры, которые обеспечивают реализацию соответствующего права за счет экономических возможностей общества при недостаточных материальных (имущественных) возможностях гражданина.
Социальные права, понимаемые в узком смысле слова, неразрывно связаны с институтом социальной защиты граждан. Именно эта группа прав наиболее общественно значима как социальная функция в государстве, именно она служит критерием социальной защищенности человека в обществе [6]. В этом заключается ее главная роль. Для конкретизации в рамках единой нормативной категории социальных прав целесообразно применять термин «социальные права, реализуемые через систему социальной защиты».

Несоответствие социально-экономических потребностей и нужд современного общества их экономическим возможностям порождает определенный социальный дисбаланс, в первую очередь, из-за ограниченного объема материальных благ. В этом случае необходимо предусмотреть полноту финансового обеспечения при реализации законодательных мер поддержки социальных прав. Вместе с тем следует учитывать, что существующая величина финансовых обеспечения законодательных мер поддержки социальной сферы должна быть достаточной для обеспечения основных прав гражданина (закрепленных в Конституции РФ) и необходимых мер по его социализации. Это финансово-правовое соотношение диктует исключительность процесса законодательного регулирования социальных прав, реализуемых через систему социальной защиты.

Описываемая уникальная категория прав имеет свои особенности, заключающиеся в том, что конкретное социальное право невозможно реализовать в абстрактной форме. В таком случае они приобретают декларативные свойства без учета законодательных, правовых механизмов реализации. Таким образом, для трактовки и восприятия конкретных видов социальных прав, осуществляемых посредством системы социальной защиты, необходимо четкое и однозначное определение объема и условий его предоставления с одновременным обеспечением его финансирования, что требует уточнения социальных критериев и нормативов. В связи с этим социальным правам присущи количественные критерии и характеристики, что находит отражение в целом ряде известных терминов «прожиточный минимум», «потребительская корзина», «государственные социальные стандарты» и т.п. 
Заключение. Следовательно, в силу индивидуальной общественной природы социальные права, реализуемые через комплекс социальных инструментов, требуют таких механизмов реализации, которые предусматривают обязательное наличие их нормативной фиксации.

Обобщая вышеизложенное, можно констатировать, что реализация социальных прав (правомочий) индивида происходит через систему социальной защиты, используя экономические возможности общества посредством осуществления предпринимательской, трудовой и иной не запрещенной законом деятельности. Реализация совокупности всех социальных прав через систему социальной защиты и определяет уровень «социальности» государства.

\section{Список источников}

1. Аграновская Е.В. Формирование рынка в России и защита прав граждан // Социальное государство и защита прав человека/ Отв. ред. Е. Л. Лукашева. М.: Издво ИГиП РАН, 1994. С. 80-90.

2. Бланкенагель А. Конституционные суды, социальные права и социальное государство // Конституционное правосудие и социальное государство. Сборник докладов. М.: Изд-во Ин-та права и публичной политики, 2003. С. 42-44.

3. Григорьев И.В., Шайхатдинов В.Ш. Право социального обеспечения: учебник и практикум для среднего профессионального образования. - М.: Издательство Юрайт, 2019. 428 c.

4. Гурлев В.В., Гурлев А.В. Социальное государство и общество. СПб.: Северная звезда, 2002. $126 \mathrm{c.}$

5. Иваненко В. А, Иваненко В.С. Социальные права человека и социальные обязанности государства: международные и конституционные правовые аспекты. СПб.: Юрид. центр Пресс, 2003. 404 с.

6. Левченко Н.А. Теория организации. Новочеркасск: ЮРГПУ (НПИ), 2015. 154 с.

7. Путило Н.В. Социальные права в постиндустриальном обществе. М.: Проспект, 2021. $120 \mathrm{c}$.

8. Фетюхин М.М. Социальное право. Курс лекций. Волгоград: ВГУ, 2007. 147 с.
9. Шеппели К.Л. Защита социальных прав с позиций реальной политики // Конституционное право: восточно-европейское обозрение. М., 2003. №1. С. 52-66.

10. Public Administration and Regional Management in Russia - Challenges and Prospects in a Multicultural Region / E.G. Popkova and K. V. Vodenko (eds.). Cham: Springer International Publishing AG, 2020. 567 p.

\section{References}

1. Agranovskaja E. V. Formirovanie rynka v Rossii i zashhita prav grazhdan [Formation of the market in Russia and protection of citizens ' rights] Social'noe gosudarstvo i zashhita prav cheloveka [The social State and the protection of human rights] In E. L. Lukasheva (eds.). Moscow: Izd-vo IGiP RAN, 1994. 80-90. (In Russ.).

2. Blankenagel' A. Konstitucionnye sudy, social'nye prava i social'noe gosudarstvo [Constitutional courts, social rights and the social state] Konstitucionnoe pravosudie i social'noe gosudarstvo. Sbornik dokladov [Constitutional justice and the social State. Collection of reports]. Moscow: Izd-vo In-ta prava i publichnoj politiki, 2003. 42-44. (In Russ.).

3. Grigor'ev I. V., Shajhatdinov V. Sh. Pravo social'nogo obespechenija: uchebnik i praktikum dlja srednego professional'nogo obrazovanija [Law of social security: textbook and practice for secondary vocational education]. Moscow: Izdatel'stvo Jurajt, 2019. 428. (In Russ.).

4. Gurlev V. V., Gurlev A. V. Social'noe gosudarstvo i obshhestvo [Social state and society]. Saint Petersburg: Severnaja zvezda, 2002. 126. (In Russ.).

5. Ivanenko V. A, Ivanenko V.S. Social'nye prava cheloveka i social'nye objazannosti gosudarstva: mezhdunarodnye i konstitucionnye pravovye aspekty [Social human rights and social obligations of the state: international and constitutional legal aspects]. Saint Petersburg: Jurid. centr Press, 2003. 404. (In Russ.).

6. Levchenko N.A. Teorija organizacii. Novocherkassk: URGPU (NPI), 2015. 154. (In Russ.).

7. Putilo N.V. Social'nye prava V postindustrial'nom obshhestve [Social rights in a post-industrial society]. Moscow: Prospekt, 2021. 120. (In Russ.). 
8. Fetjuhin M.M. Social'noe pravo. Kurs lekcij [Social law. A course of lectures]. Volgograd: VGU, 2007. 147. (In Russ.).

9. Sheppeli K.L. Zashhita social'nyh prav s pozicij real'noj politiki [Protection of social rights from the standpoint of real politics] Konstitucionnoe pravo: vostochno-evropejskoe obozrenie [Constitutional law: Eastern Euro- pean review]. Moscow, 2003; (1):52-66. (In Russ.).

10. Public Administration and Regional Management in Russia - Challenges and Prospects in a Multicultural Region / E.G. Popkova and K. V. Vodenko (eds.). Cham: Springer International Publishing AG, 2020. 567 p.

Статья поступила в редакцию 28.08.2021; одобрена после рещензирования 15.09.2021; принята к публикаиии 20.09.2021.

The article was submitted on 28.08.2021; approved after reviewing on 15.09.2021; accepted for publication on 20.09.2021.
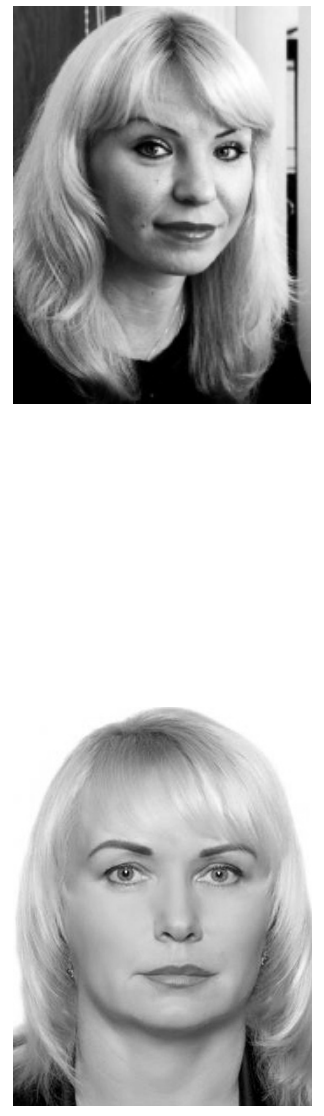

\section{ИНФОРМАЦИЯ ОБ АВТОРАХ}

Левченко Наталья Александровна - кандидат экономических наук, доцент кафедры «Социальные и гуманитарные науки», Южно-Российский государственный политехнический университет (НПИ).

Россия, г. Новочеркасск, ул. Просвещения, 132

Natalya A. Levchenko - Candidate of Economic Sciences, Associate Professor of «Social Sciences and Humanities» chair, South-Russian State Polytechnic University (NPI).

132 Prosveshcheniya st., Novocherkassk, Russia

Иващенко Светлана Александровна - кандидат экономических наук, доцент, Южно-Российский государственный политехнический университет (НПИ) имени М.И. Платова.

Россия, г. Новочеркасск, ул. Просвещения, 132

Svetlana A. Ivashchenko - Candidate of Economic Sciences, Associate Professor, South-Russian State Polytechnic University (NPI).

132 Prosveshcheniya st., Novocherkassk, Russia 


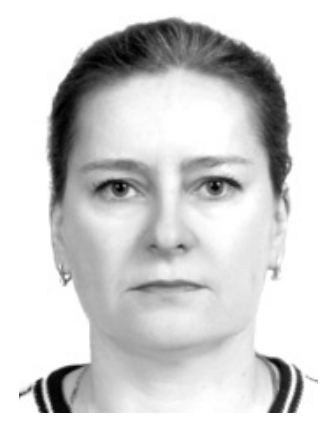

Романенко Елена Валерьевна - старший преподаватель кафедры «Производственный и инновационный менеджмент», Южно-Российский государственный политехнический университет (НПИ).

Россия, г. Новочеркасск, ул. Просвещения, 132

Elena V. Romanenko - Senior Lecturer of the Department «Production and Innovation Management», South-Russian State Polytechnic University (NPI).

132 Prosveshcheniya st., Novocherkassk, Russia

Вклад авторов:

Левченко Н. А. - научное руководство; концепция исследования; развитие методологии; написание исходного текста; итоговые выводы.

Иващенко С. А. - развитие методологии; написание исходного текста; итоговые выводы.

Романенко Е. В. - доработка текста; итоговые выводы.

Contribution of the authors:

Levchenko N.A. - scientific management; research concept; development of methodology; writing the source text; final conclusions.

Ivashchenko S. A. — development of methodology; writing of the source text; final conclusions. Romanenko E. $V$. - revision of the text; final conclusions. 